\title{
AVALIAÇÃO NAS INSTITUIÇÕES DE FORMAÇÃO DE PROFESSORES: FORMAS AVALIATIVAS REFLEXIVAS, CONSTRUTIVAS, DEMOCRÁTICAS E EMANCIPADORAS
}

\section{ENSAIO TEÓRICO}

MIRIONE, Domingos Carlos ${ }^{1}$

MIRIONE, Domingos Carlos. Avaliação nas instituições de formação de professores: Formas avaliativas reflexivas, construtivas, democráticas e emancipadoras. Revista Científica Multidisciplinar Núcleo do Conhecimento. Ano 04, Ed. 07, Vol. 01, pp. 148-162. Julho de 2019. ISSN: 2448-0959

\section{RESUMO}

A avaliação é uma das principais competências do processo docente que extrapola a sala de aula. As instituições de ensino vocacionadas a formação de professores, precisam prestar atenção a essa componente do processo docente educativo. No entanto, a avaliação nas instituições do ensino superior, vocacionadas à formação de professores em Moçambique parece um exercício exclusivo dos docentes, excluindo o estudante na avaliação tanto do seu próprio desempenho, como dos outros. Este ensaio visa estimular a reflexão sobre a importância de formas de avaliação reflexivas, construtivas, democráticas e emancipadoras com destaque para a autoavaliação e a avaliação mútua entre os estudantes e propor algumas abordagens dessas duas formas de avaliação com especial enfoque nas instituições de formação de professores e com exemplos virados ao curso de Educação Física e Desporto da extinta Universidade Pedagógica - Delegação de Nampula.

Palavras-chave: avaliação, teste, medida.

\footnotetext{
${ }^{1}$ Mestre em Treino Desportivo de Crianças e Jovens, Diretor do Curso de Educação Física e Desporto da Universidade Rovum - Moçambique.
} 


\section{INTRODUÇÃO}

A avaliação é uma das 10 novas competências do processo docente (PERRENOUD, 2000), e uma das questões que lida com ela até fora da sala de aula, no momento da avaliação do seu desempenho profissional.

A Universidade Pedagógica de Moçambique é vocacionada na formação de professores para diferentes níveis e sistemas de ensino, no entanto, as formas de avaliação vigentes parece ignorar-se que os estudantes que hoje formamos lidarão com o processo de avaliação no seu dia a dia no futuro.

Apesar de muitas críticas aos paradigmas tradicionais de avaliação, continua sendo prática o tipo de avaliação tradicional nas nossas universidades.

Poucos docentes aplicam a avaliação diagnóstica e se aplicam muitos não fazem uso da informação que ela traz. Pior ainda, nunca se fala de autoavaliação nem de avaliação mútua nas nossas universidades.

Será que essas formas de avaliação têm alguma utilidade para o futuro professor como parte das competências docentes?

O presente trabalho pretende estimular a reflexão sobre a importância de formas de avaliação reflexivas, construtivas, democráticas e emancipadoras com destaque para a autoavaliação e a avaliação mútua entre os estudantes e propor algumas abordagens dessas duas formas de avaliação.

Para isso, apoiou-se em vários artigos que versam sobre processos avaliativos reflexivos e construtivos no ensino superior. 


\section{DESENVOLVIMENTO}

\section{CONCEITO DE AVALIAÇÃO}

Segundo KRAEMER (2005), a palavra avaliação vem do latim a+valere que significa atribuir valor e mérito ao objeto em estudo. Essa ideia é corroborada pelo Dicionário eletrônico Houaiss da Língua Portuguesa 3.0 que define avaliar por um lado como estabelecer a valia, o valor ou preço de alguma coisa, por outro lado, como determinar, ter ideia, da quantidade, qualidade, extensão, intensidade, etc, de algo.

Atribuir um valor, é emitir um juízo e esse juízo só pode ser emitido depois de se determinar, e essa determinação, pode ser feita por comparar o objeto a avaliar com uma referência. Daí que para muitos autores, avaliar é comparar o resultado ou o desempenho do estudante e os objetivos previamente definidos (TYLER, 1949, BLOOM et. al., 1971, CARDINET, 1993)

Quando comparamos um objeto com uma escala como referência estamos a medir, pelo que entender a avaliação como o ato de comparar um desempenho com os objetivos propostos, colocamos a avaliação como sinônimo de medição ou mensuração.

Quase sempre para medir algo necessitamos de um instrumento, e quando se trata de medir ou avaliar o processo de ensino aprendizagem muitas vezes são usados testes como instrumentos de medida.

Os testes nos ajudam a recolher a informação sobre o objeto em análise. Essa informação deve ser processada, sistematizada e interpretada para depois emitir-se um juízo sobre o objeto.

Por muito tempo esse juízo foi baseado em critérios ou normas. Segundo SOUZA (2012), os testes criteriais são usados para verificar o desempenho do indivíduo em relação a um objetivo concreto que expressa um domínio, por meio de um critério previamente estabelecido, ao passo que, testes normativos tem por objetivo a 
comparação do rendimento de alguns estudantes com outros, identificando os que são mais capazes e os que são menos capazes.

No entanto, a avaliação não termina com o juízo emitido, não basta saber que este estudante está na melhor ou pior posição na escala classificativa, o juízo emitido tem que nos levar a ação, a tomada de decisão.

Para PERRENOUD (1999) e SAUL (1988)[2], a avaliação é concebida como processo/instrumento de coleta de informações, sistematização e interpretação das informações, julgamento de valor do objeto avaliado e, por fim, tomada de decisão.

Mas a decisão não pode ser apenas aprovação ou reprovação. É verdade que o sistema educativo impõe esse julgamento final, mas isso pode-se evitar se a avaliação for sistemática e contínua.

Uma avaliação discriminatória que traduz todo resultado em aprovação ou reprovação é excludente, autoritária e antidemocrática e, ao mesmo tempo, vista pelos docentes que tradicionalmente foram atribuídos o poder de avaliar como um instrumento de exercício de poder. Daí que, atualmente essa perspetiva de avaliação ditatorial é alvo de muitas críticas (SOUZA, 2012).

A avaliação deve ser um auxílio para se saber quais objetivos foram atingidos, quais ainda faltam e quais as interferências do docente podem ajudar o aluno (LUCKESI, 2002).

"A avaliação da aprendizagem ultrapassa o estágio da aferição dos resultados (medida), da obtenção da informação (verificação), da constatação de acertos e erros (testagem) - para se tornar num processo de interpretação e tomada de decisão ante o conjunto de informações obtidas ${ }^{[3]}$ ".

Isso nos remete a análise da função da avaliação no processo de ensino aprendizagem. 


\section{FUNÇÃO DA AVALIAÇÃO E TIPOS DE AVALIAÇÃO}

Das várias fontes consultadas, encontra-se uma relação entre as funções de avaliação e os tipos de avaliação, razão pela qual no presente trabalho abordam-se as duas temáticas junto.

TREVELIN \& NEIVA (2011) diz que a avaliação deve cumprir três funções didáticapedagógica que são: a função diagnóstica, a função formativa e a função somativa.

Essas três funções de avaliação estão relacionadas aos tipos de avaliação referenciados por vários autores pelos mesmos nomes (ROSADO \& SILVA, 2012, GARCIA, 2009, GRIZENDI et al, 2008): Avaliação diagnóstica que tem a função diagnóstica, avaliação formativa que tem a função formativa e avaliação somativa que tem a função somativa.

\section{A AVALIAÇÃO DIAGNÓSTICA}

Aplicada no início do período letivo, cumpre a função diagnóstica, porque a utilizamos para identificar os conhecimentos e/ou habilidades prévias dos estudantes que poderão nos ajudar a prognosticar os possíveis problemas de aprendizagem que estes estudantes poderão enfrentar, e encontrar o ponto de partida do processo de ensino aprendizagem. A avaliação diagnóstica também pode desempenhar a função motivadora dependendo de como o professor e o estudante podem fazer uso dos resultados da mesma (ROSADO \& SILVA, 2012).

No entanto, apesar de tanta importância que pode ter esta modalidade de avaliação, é pouco usada nas universidades moçambicanas, talvez por um lado seja pela inconsciência dos docentes já que a maioria não passou por uma formação específica para a docência no ensino superior e outros por falta de tempo já que lecionam várias cadeiras em vários cursos acadêmicos para além de prestar os serviços de docência em duas ou mais universidades.

Avaliação diagnóstica deveria ser o ponto de partida do processo de ensino aprendizagem, com uma abordagem reflexiva, participativa, democrática e 
individualizada, onde através do diálogo interativo, tanto o estudante, como o docente, toma consciência dos caminhos a seguir e do esforço a empreender para o alcance dos objetivos curriculares (HOFFMANN, 1994 apud BERBEL et. al., 2006).

Um exemplo concreto que ilustra a necessidade de dar importância a avaliação diagnóstica na nossa universidade em especial no curso de Educação Física e Desporto é a procedência dos estudantes admitidos ao curso.

Embora por norma todos os estudantes admitidos deveriam passar por exames de admissão e só poderiam ser candidatos a esse exame, o estudante que tenham tido a disciplina de Biologia no ciclo precedente, o que se constata é que um número significativo é admitido ao curso por via parceria institucional ou bolsa de estudos sem os mesmos passarem por exame de admissão para além de não haver rigor na observação dos requisitos, havendo estudantes que concluíram o nível médio pela secção das letras ou pelo ensino técnico profissional sem muita relação com as cadeiras curriculares do curso de Educação Física.

Esses estudantes desprovidos da base teórica para o curso de educação física poderão se encontrar na mesma sala com aqueles que concluíram o ensino médio geral pela secção com Biologia conformando uma turma bastante heterogênea o que faz da avaliação diagnóstica um instrumento importante a ser usado pelo docente.

No entanto, sempre o seu uso tem que estar em consonância com as teorias modernas do processo de ensino aprendizagem onde o estudante é o protagonista do processo, envolvendo-o na avaliação e análise do seu conhecimento inicial e consciencializá-lo dos desafios que terá para corresponder aos objetivos curriculares.

\section{AVALIAÇÃO FORMATIVA}

A avaliação formativa, cumpre a função formativa, de controle e reguladora porque ao decorrer ao longo do processo e de forma continuada, informa tanto ao docente como ao aluno sobre os resultados que estão sendo alcançados no decurso do processo de ensino aprendizagem. Essa avaliação garante o feedback da ação dos intervenientes 
no processo (aluno-docente) e com base nela pode-se saber as dificuldades, deficiências e insuficiências que está tendo o processo e encontrar mecanismos conjuntos de como superar. (TREVELIN \& NEIVA, 2011).

Segundo GRIZENDI et. al., (2008), acredita-se que avaliação formativa, por permitir alterações no decorrer do processo, poderá ser mais coerente e ser capaz de promover alterações no decorrer do processo de ensino-aprendizagem à medida que é possível, com base nos resultados obtidos, realizar mudanças no percurso para mais ou para menos.

De facto, a avaliação formativa, cumpre a finalidade de aperfeiçoar o processo de ensino-aprendizagem

Como o próprio nome diz, esta modalidade se situa no centro da ação de formação, ao caracterizar-se como informativa (informa os atores do processo educativo); corretiva (corrige a ação, modificando-a, quando for necessário); e, propositiva (conhecidas as dificuldades do aluno e das condições, trabalha-se rumo a uma utopia promissora) ${ }^{[4]}$.

Como se pode notar, pelas considerações dos autores, a avaliação formativa é sem dúvida uma das mais importantes senão a mais importante de todas. É nesta avaliação que se aplica as palavras de GRIZENDI et. al., (2008), quando afirmam que "o objetivo maior do ato de avaliar deve ser a busca da melhoria contínua da aprendizagem". No entanto, igual que avaliação diagnóstica, avaliação formativa é menos usada pelos professores do ensino superior não só no nosso país como também em outros países como mostram alguns estudos do estrangeiro (RIBEIRO \& FILHO, 2011, GARCIA, 2009, SOUZA, 2012).

Porque a avaliação formativa é menos usada ou menos diversificada no nosso ensino superior? As principais causas podem estar relacionadas com os fatores mencionados na avaliação diagnóstica: o tempo e as atitudes tradicionais que ainda emperram nas mentes dos docentes. 
A exiguidade de docentes para um sistema em expansão, e a busca incessante pelo docente de manter um status social digno frente a uma remuneração mensal relativamente baixa, faz com que muitos docentes tenham contratos de trabalho com várias instituições restando pouco tempo para uma abordagem didático-pedagógica progressista e emancipadora do processo de ensino-aprendizagem. Daí que para muitos docentes do ensino superior no nosso país, toda forma de avaliação é reduzida a um seminário, dois testes escritos e um exame.

E em todas essas formas de avaliação, o papel do docente é decisório e muitas vezes ditatorial. É o docente que estabelece as formas de avaliação e os critérios de avaliação, sem nenhuma consulta nem espaço para negociação com os estudantes. Essa atitude sem dúvida choca por completo com as teorias modernas de aprendizagem que colocam o estudante como protagonista da sua própria aprendizagem.

Pior ainda, nos seminários os critérios são mais subjetivos que objetivos e ao final essa subjetividade tem que ser traduzida em nota, levando a alguns estudantes à revolta e desmotivação por sentirem-se injustiçados ou por notarem algum favoritismo por parte do docente.

Mesmo inconformado, o estudante vê-se em frente de um docente que pelos poderes que Ihe foram conferidos não pode desafiá-lo para não sentencia-lo a reprovação.

Diante duma ditadura desta natureza em que a nota da avaliação não é negociada nem discutida entre os intervenientes do processo docente-estudante e estudanteestudante, a autorreflexão do processo por parte do estudante só resulta em desmotivação porque ele pode ter argumentos, mas que esses argumentos, não são válidos para o docente ou não existe espaço para os expor.

O não envolvimento do estudante na avaliação da sua própria aprendizagem, sobretudo para aqueles que estão se formando como futuros professores, para além de ser uma ditadura, os estudantes ficam desprovidos de um espaço para aprender a avaliar e futuramente quando forem professores só poderão reproduzir a forma de 
avaliar dos seus docentes da graduação. Isso afeta as competências do docente que segundo PERRENOUD (2000), uma das competências para ensinar é administrar a progressão das aprendizagens por "observar e avaliar os alunos em situação de aprendizagem, de acordo com uma abordagem formativa".

Como podemos usar a avaliação formativa para melhorar o processo de ensino aprendizagem e preparar os estudantes do ensino superior como futuros professores que se empenharão entre outras competências em avaliar os seus alunos?

PERRENOUD (2000), sugere que a competência específica de observar e avaliar os alunos em situação de aprendizagem, de acordo com uma abordagem formativa, o docente deve estimular a autoavaliação, a avaliação mútua, a metacognição, ter uma percepção da classe para (re)orientar o ensino.

O autor acima citado sugere aqui duas formas de avaliação, a autoavaliação e a avaliação mútua, e uma estratégia que pode reforçar a autoavaliação, a metacognição. Podemos acrescentar a essa lista de formas de avaliação, o portfólio.

São essas formas de avaliação que deveríamos introduzir ou potenciar no nosso sistema de ensino superior por constituírem formas avaliativas reflexivas, integradoras e transformadoras.

Mas antes de irmos aos pormenores do que são e como se podem aplicar no nosso contexto, analisemos sinteticamente o terceiro tipo de avaliação, a somativa.

\section{AVALIAÇÃO SOMATIVA}

De acordo com KRAEMER (2005), avaliação somativa, "corresponde a um balanço final, a uma visão de conjunto relativamente a um todo, sobre o qual, até aí, só haviam sido feitos juízos parcelares".

É realizada ao final do processo, e serve para verificar em que grau foram alcançados os objetivos propostos, pelo que, julga e classifica o estudante segundo o seu aproveitamento ao final de uma unidade, semestre ou curso (SANTOS, 2005 citado 
por GRIZENDI et al., 2008). Sendo um juízo final, esta avaliação não dá espaço para uma reorganização do processo ou reorientar o estudante (RAPILAEL, 1994), mas é o tipo de avaliação mais adotado pelos docentes do ensino superior, dada a sua praticidade (GRIZENDI et al., 2008).

Apesar de muitas críticas, a avaliação somativa ainda constitui o principal instrumento "para se conceder a certificação aos alunos ou selecionar e classificar candidatos em concursos ou em exames em larga escala" (FELICE, 2011), é por isso que essa avaliação é conhecida também por outros autores como avaliação certificativa (PERRENOUD, 1999 citado por SANTOS \& GOMES, 2006; BLOOM et al., 1971 citados por ROSADO \& SILVA, 2010; FERNANDES, 2006).

\section{FORMAS DE AVALIAÇÃO REFLEXIVAS, CONSTRUTIVAS, DEMOCRÁTICAS E EMANCIPADORAS}

A superioridade da avaliação formativa sobre a avaliação somativa ou certificativa, podemos encontrar nos estudos feitos por OLIVA et al., (2011) em três centros universitários de formação de professores em cursos de graduação onde aplicou sistemas de avaliação formativas e somativas ao longo do curso acadêmico para ver o efeito de cada tipo de avaliação na aprendizagem dos estudantes e os resultados mostraram que os estudantes que escolheram a avaliação formativa, tiveram melhor rendimento acadêmico do que aqueles que escolheram exclusivamente avaliação somativa.

Nas teorias atuais de aprendizagem, centradas na aprendizagem significativa, "para assegurar a aprendizagem reflexiva de conteúdos concretos, quem aprende necessita explicar, argumentar, perguntar, deliberar, discriminar, defender suas próprias ideias e crenças e, simultaneamente, aprender a avaliar" (SILVA, 2002)

É por isso que defendo o uso da autoavaliação e avaliação mútua entre os estudantes no ensino superior em Moçambique. 
Essas formas de avaliação integram-se dentro de avaliações reflexivas, construtivistas, democráticas e emancipadoras.

São reflexivas porque envolve a metacognição ${ }^{[5]}$ por parte do estudante no momento em que ele faz a autocorreção daquilo que fez, e são construtivistas porque transformam o espaço educativo em um "ambiente de superação de desafios pedagógicos, o que dinamiza e significa a aprendizagem, que passa a ser compreendida como construção de conhecimentos e desenvolvimento de competências"(SILVA, 2002). Segundo GREENE (1975) apud SOUZA, (2012), a autorreflexão como parte da autoavaliação, contribui para a construção de significados sobre si, os outros e o mundo ou mesmo a reformulação desses significados.

São democráticas porque envolve a todos os intervenientes na tomada de decisão, tanto o docente que cria as condições para os procedimentos avaliativos ao mostrar aos estudantes que competências se espera que eles adquiram, que utilidade tem as tais competências no contexto histórico social em que se encontram e como se devem evidenciar no processo de ensino aprendizagem em que eles próprios são agentes protagonistas. E também são democráticas ao ser lugar de negociação na definição dos seus objetivos, critérios, instrumentos e dinâmica e por ser o território em que os educandos têm a oportunidade de aplicarem os seus conhecimentos e apresentarem as suas dúvidas, inseguranças, incertezas (OLIVA et. al., 2011), "o dever do docente de avaliar, corresponde ao direito do estudante a ser informado e a participar nas decisões que lhe afetam".

São emancipadoras, porque promove uma atitude crítica e autocrítica sem simplesmente alienar-se às imposições ditatoriais do docente. Liberta o estudante da visão da avaliação como instrumento de poder do docente. Para AZEVEDO \& SHIGUNOV (2000), "a emancipação pode ser entendida como um processo contínuo de libertação do estudante das condições limitantes de suas capacidades racionais críticas e até mesmo o seu agir no contexto sociocultural e o dota de capacidade de questionar e analisar as condições e a complexidade de diferentes realidades de forma fundamentada permitindo uma constante autoavaliação do envolvimento objetivo e subjetivo no plano individual e situacional". De facto, "ninguém emancipa, 
desenvolve autonomia, desenvolve criação se não tiver oportunidade de agir com autonomia, com criatividade, de maneira emancipadora" (MIRALHA, 2008).

\section{A AUTOAVALIAÇÃO E AVALIAÇÃO MÚTUA}

A autoavaliação é um processo pelo qual um indivíduo, além de avaliar uma produção, uma ação, ou uma conduta da qual ele é o autor, também avalia as suas capacidades, os seus gostos, o seu desempenho, as suas competências e habilidades. É um processo cognitivo complexo, pelo qual um indivíduo (aprendiz ou professor) faz um julgamento, com o objetivo de um melhor conhecimento pessoal, visando ao aperfeiçoamento das suas ações e ao seu desenvolvimento cognitivo (SILVA et. al., 2007).

Como podemos usar a autoavaliação do estudante no ensino superior?

O ponto de partida, é sabermos que a autoavaliação é uma avaliação criada e construída pelo estudante (SOUZA, 2012), pelo que a mesma tem de ser elaborada com participação do próprio estudante.

Por exemplo, na avaliação diagnóstica, logo no primeiro dia de apresentação do docente e do plano curricular da cadeira, o docente pode colocar três perguntas aos alunos para que ponham por escrito e de forma sintética as suas opiniões:

- O que sabem da cadeira?

- Que expectativa tem sobre a cadeira?

- Como vão avaliar o alcance das tais expectativas?

Depois de apresentar os conteúdos do plano curricular da cadeira, os estudantes podem voltar a responder por escrito e de forma sintética, duas perguntas:

- Que problemas concretos da comunidade onde vivem e da sua vida pessoal, achas que os conteúdos curriculares poderão ajudar-lhe a resolver?

- Como pensas aplicar o conhecimento que poderá adquirir nesta cadeira na sua vida? 
Essas duas últimas perguntas também poderão ser colocadas ao longo do processo e de forma particularizada ao final de cada unidade didática e no pretérito perfeito, pelo que as respostas dos estudantes devem ser arquivadas para que o docente possa ir-se apoiando nelas ao avaliar o processo todo.

$\mathrm{Na}$ avaliação formativa, quando o docente dá um teste aos estudantes, a correção do mesmo deve ser feita pelos próprios estudantes.

Depois do teste, o estudante fica com uma cópia tanto do rascunho como do enunciado para ir refletir sobre o teste em casa. Em casa, poderá consultar fontes adicionais, manuais, notas das aulas assistidas ou debater com colegas da turma e corrigir de forma fundamentada o teste. Isso significa não só escrever a resposta da questão colocada, mas também fundamentá-la, o porquê da resposta e o que lhe teria induzido ao erro no momento que fez o teste. Essa reflexão poderá consolidar o conhecimento do estudante sobre a matéria avaliada do que simplesmente o docente dizer como deveriam ter respondido. Para além de que ao dizerem o que teria the induzido ao erro, poderá ajudar ao docente a avaliar as qualidades das perguntas formuladas nos testes.

Outra maneira de promover avaliação reflexiva nos estudantes é, por exemplo, quando a correção for feita na sala de aulas, no momento da correção do teste, cada questão ser corrigida por um estudante que tenha errado a mesma, com perguntas reguladoras do docente para levar o estudante à resposta correta. Com aplicação destas perguntas ao estudante, os demais que erraram a mesma questão, ficam também a procurar as respostas o que permite que todos que não tenham se saído bem naquela questão estejam envolvidos na autorreflexão e redirecionamento da sua aprendizagem.

Nos trabalhos de pesquisa em grupo, o docente pode pedir que cada integrante do grupo, anexe uma página ou menos, onde descreve a sua participação no trabalho do grupo e o nível de participação em relação aos demais membros. Isso incentivará a participação de todos no trabalho em grupo embora não possa eliminar por completo aqueles estudantes que os seus nomes só aparecem no trabalho não por terem 
participado na produção do mesmo, mas por simplesmente serem membros desse grupo.

Nos seminários, é importante que o estudante avalie o seu próprio desempenho tanto em relação ao grupo assim como em relação aos critérios de avaliação da matéria previamente estabelecidos em conjunto. A proposta de avaliação do estudante tem que ser fundamentada e através de perguntas reguladoras feitas pelo docente poderão chegar a avaliação final do desempenho do estudante no seminário. A negociação é muito importante nos seminários por terem um carácter subjetivo e evita conflito entre docente e estudante assim como a desmotivação do próprio estudante com o processo.

Ainda nos seminários pode-se incluir a avaliação mútua entre os estudantes. Quando um grupo apresenta o seu trabalho no seminário, outro grupo pode ficar como avaliador com base nos critérios previamente estabelecidos e avaliação do grupo tem que ser igualmente fundamentada.

A avaliação final nesse caso será o resultado da intervenção de todos ou pelo menos três partes: o grupo que apresenta, o grupo que avalia e a moderação do docente.

A participação dos estudantes no processo de avaliação poderá capacitá-lo para o seu trabalho docente futuro onde a avaliação será parte constante do processo.

Ao final do processo de ensino aprendizagem poderá se pedir aos estudantes que produzam um relatório com base no seu portfólio, onde poderão destacar os pontos essenciais da aprendizagem da cadeira para além de refletir sobre as questões colocadas no início do processo, ou seja, avaliar como a cadeira cumpriu as suas expetativas, que expetativas não foram cumpridas e como pensam suprir as lacunas que acha que ainda persistem.

Numa avaliação dessa natureza, a nota não é o mais importante, mas sim a aprendizagem. Recordemos que nem sempre a nota reflete o aprendido, aprendizagem induz a mudança de comportamento, a forma de ver as coisas, mas o que acontece é que com as formas vigentes de avaliação nas nossas universidades, 
o aluno só estuda para a nota, obrigando-o a memorizar e até a procurar formas fraudulentas de como conseguir a tal nota. Ele fica preocupado com a nota e não com a aprendizagem em si e depois de avaliação mesmo que tenha a máxima pontuação, passado algumas semanas ou meses já se esqueceu de tudo.

Daí que formas de avaliação reflexivas podem promover a aquisição de conhecimentos sólidos que podem ser traduzidos em habilidades e competências úteis na vida prática.

\section{CONSIDERAÇÕES FINAIS}

Os estudos analisados mostram a necessidade de sairmos da "teoria" de avaliação reflexiva que tem o próprio estudante como protagonista para uma "prática" de avaliação reflexiva que tem o estudante como protagonista.

Muitos docentes, tem consciência da importância da aprendizagem centrada no aluno, mas muitas vezes as práticas contradizem com as teorias e as sugestões apresentadas no presente ensaio poderão ajudar os docentes do ensino superior a materializar certas teorias de avaliação reflexiva que poderão também ajudar ao estudante a capacitar-se para a futura função docente.

Que o estudante seja protagonista da sua própria aprendizagem não só no processo de aquisição dos conhecimentos, habilidade e competências, mas também na avaliação do tais conhecimentos, habilidades e competências através de autoavaliação e avaliação mútua.

\section{REFERÊNCIAS BIBLIOGRÁFICAS}

AZEVEDO, Edson Souza de; SHIGUNOV, Viktor. Reflexões sobre as abordagens pedagógicas em Educação Física. Kinein, Florianópolis, v. 1, n. 1, set./dez. 2000.

BARBEL, Aparecida Navas, OLIVEIRA, Cláudia Chueire de, VASCONCELLOS, Maura Maria Morita. Práticas Avaliativas consideradas positivas por alunos do ensino 
superior: aspectos didáticos pedagógicos. Estudos em Avaliação Educacional, v. 17, n. 35 , set./dez. 2006

FELICE, Maria Inés Vasconcelos. Qual o lugar da avaliação da aprendizagem na formação do Professor de línguas? Anais do SILEL. Volume 2, Número 2. Uberlândia: EDUFU, 2011.

FERNANDES, Domingos. Vinte anos de avaliação das aprendizagens: Uma síntese interpretativa de artigos publicados em Portugal. Revista portuguesa de pedagogia ano 40-3, 2006, 289-348

GARCIA, Joe. Avaliação e aprendizagem na educação superior. Est. Aval. Educ., São Paulo, v. 20, n. 43, maio/ago. 2009.

GRIZENDI, José Carlos Miranda, SILVA, Judilma Aline Oliveira e FERREIRA, Victor Cláudio Paradela. A contribuição da avaliação continuada para a melhoria do desempenho discente: relato de uma experiência. Juiz de Fora, n. 06, Ago./Set. 2008.

KRAEMER, Maria Elizabeth Pereira. A avaliação da aprendizagem como processo construtivo de um novo fazer. Contabilidade. 2005. Disponível em: http://www.gestiopolis.com/canales5/fin/avalica.htm

Metodologia do Ensino Superior. Universidade da Amazônia. Disponível em: http://arquivos.unama.br/nead/pos_graduacao/direito_processual/met_ens_sup/Aula 10/conceito_principios.htm

MIRALHA, Jussara Oliveto. A prática pedagógica de professores do ensino fundamental na perspectiva de uma educação de qualidade para todos. Dissertação de Mestrado apresentada ao Programa de Pós-graduação em Educação da Faculdade de Ciências e Tecnologia, UNESP/Campus de Presidente Prudente, como exigência parcial para obtenção do título de Mestre em Educação. 2008

OLIVA, F. J. Castejón, LÓPEZ-PASTOR, V. M., CLEMENTE, J.A. Julián et al. Evaluación formativa y rendimiento académico en la formación inicial del profesorado 
de educación física. Rev.int.med.cienc.act.fís.deporte- vol. 11 - número 42 - junio 2011.

PERRENOUD, Philippe. 10 Novas Competências para Ensinar, Artmed. 2000. Disponível

em: http://efpava.cursos.educacao.sp.gov.br/Resource/282801,55A,1E7/Assets/Portugue s/pdf/por_m01t07.pdf. acessado no dia 26/04/2014

RAFHAEL, Hélia Sónia. Avaliação, questão técnica ou política. Circuito PROGRAD da UNESP, 1994.

Disponível em:http://annachrist.wikispaces.com/file/view/Avalia\%C3\%A7\%C3\%A3o.rtt/3341812 9/Avalia\%C3\%A7\%C3\%A3o.rtf. acessado no dia 26\&04\&2014

RIBEIRO, Luis Roberto de Camargo e FILHO, Edmundo Escrivão. Avaliação formativa no ensino superior: um estudo de caso. Acta Scientiarum. Human and Social Sciences. Maringá, v. 33, n. 1, p. 45-54, 2011

ROSADO, António \& SILVA, Catarina. Conceitos básicos sobre avaliação das aprendizagens. 2010 disponível em: http://home.fmh.utl.pt/ arosado/ESTAGIO/conceitos.htm

SANTOS, Leonor \& GOMES, Anabela. Apropriação de critérios de avaliação: um estudo com alunos do $7^{\circ}$ ano de escolaridade. Revista portuguesa de pedagogia ano 40-3, 2006, 011-048

SILVA, Janssen Felipe da. Avaliação do ensino e da aprendizagem numa perspectiva formativa reguladora. 2002 Disponível em: < http://smeduquedecaxias.rj.gov.br/nead/Biblioteca/Forma\%C3\%A7\%C3\%A30\%20Co ntinuada/Avalia\%C3\%A7\%C3\%A3o/janssen1.pdf >. Acesso em: 19 de Junio 2017

SOUZA, Ana Maria de Lima. Avaliação da Aprendizagem no Ensino Superior: Aspectos Históricos. Revista Exitus • Volume 02 • n 01 • Jan./Jun. 2012. Disponível em: http://www.ufopa.edu.br/revistaexitus/revistas/volume-ii/artigos/avaliacao-daaprendizagem-no-ensino-superior-aspectos-historicos/view. 
TREVELIN, Ana Teresa Colenci e NEIVA, Jaqueline Santos Feliciano da Silva. Estilos de Aprendizagem e Avaliação no Ensino Superior. In: VI Workshop de Pós-Graduação e Pesquisa do Centro Paula Souza - ISSN: 2175-1897. 09 e 10 de novembro de 2011.

2. Citados pelo manual Metodologia do Ensino Superior da Universidade da Amazônia disponível

em http://arquivos.unama.br/nead/pos_graduacao/direito_processual/met_ens_sup/Aula 10/conceito_principios.htm

3. Manual de Metodologia do Ensino Superior da Universidade de Amazônia

4. Metodologia do Ensino Superior da Universidade da Amazônia disponível em http://arquivos.unama.br/nead/pos_graduacao/direito_processual/met_ens_sup/Aula 10/conceito_principios.htm

5. Processo mental interno através do qual o próprio estudante toma consciência dos diferentes momentos e aspectos da sua atividade cognitiva. Um olhar crítico consciente sobre o que se faz enquanto se faz. (SANTOS, S/D)

Enviado: Maio, 2019.

Aprovado: Julho, 2019. 